\title{
Can Physical Activity Reduce the Need of Medications for Diabetes Mellitus Management?
}

\section{Louay Labban*}

FADA, CCN, CNC, RD, A'Sharqyiah University, Ibra, Oman

\begin{abstract}
Diabetes Mellitus is considered a major chronic disease and its complications have become a main cause of morbidity and mortality worldwide. The goal of treatment in type 2 diabetes is to achieve and maintain optimal BG lipid, and blood pressure (BP) levels to prevent or delay chronic complications of diabetes. Many people with type 2 diabetes can achieve BG control by following a nutritious meal plan and exercise program, losing excess weight, implementing necessary self-care behaviors, and taking oral medications, although others may need supplemental insulin. Recently, studies have started to focus on the relationship between exercise and Insulin dependent Diabetes Mellitus (IDDM). Several studies have shown reduced insulin dosage with increased physical activity along with better glycemic control. In fact, moderate to vigorous activity has been associated with greater overall fitness, an increased fat free mass, and decreased glycosylated hemoglobin (HbA1c) levels in people with type $1 \mathrm{DM}$. That exercise could act by protecting islets during the onset of the disease, because in animal models of type 2 DM, long-term aerobic exercise resulted in increased islet $\beta$-cell proliferation, increased $\beta$-cell mass, and a partial sparing of the abnormal islet morphology noted in the sedentary diabetic rats. Exercise blocked the age-associated morphological changes in the pancreas, including multi lobulated, fibrotic islets. BG reductions are related to the duration and intensity of the exercise, pre exercise control, and state of physical training. Although previous PA of any intensity generally exerts its effects by enhancing uptake of BG for glycogen synthesis and by stimulating fat oxidation and storage in muscle, more prolonged or intense PA acutely enhances insulin action for longer periods. Women diagnosed with GDM are at substantially increased risk of developing type 2 diabetes; therefore, PA may be considered a tool to prevent both GDM and possibly type 2 diabetes at a later date.
\end{abstract}

Keywords: Diabetes; Type 1 Diabetes; Type 2 Diabetes; Gestational diabetes; Exercise; Physical activity

\section{Introduction}

Diabetes Mellitus is considered a major chronic disease and its complications have become a main cause of morbidity and mortality worldwide. T2DM is defined by impaired glucose tolerance, chronic hyperglycemia, altered insulin secretion, and complications that come from induction of oxidative stress [1]

The goal of treatment in type 2 diabetes is to achieve and maintain optimal blood glucose (BG), lipid, and blood pressure (BP) levels to prevent or delay chronic complications of diabetes [2]. Many people with type 2 diabetes can achieve BG control by following a nutritious meal plan and exercise program, losing excess weight, implementing necessary self-care behaviors, and taking oral medications, although others may need supplemental insulin [3]. Diet and physical activity (PA) are central to the management and prevention of type 2 diabetes because they help treat the associated glucose, lipid, BP control abnormalities, as well as aid in weight loss and maintenance. When medications are used to control type 2 diabetes, they should augment lifestyle improvements, not replace them.

Recently, studies have started to focus on the relationship between exercise and Insulin dependent Diabetes Mellitus (IDDM). In general, several studies have shown reduced insulin dosage with increased physical activity [4] along with better glycemic control [5]. In fact, moderate to vigorous activity has been associated with greater overall fitness, an increased fat free mass, and decreased glycosylated hemoglobin (HbAlc) levels in people with type $1 \mathrm{DM}[6,7]$. In a randomized study of 196 adults with type $1 \mathrm{DM}$, those that exercised moderately once to three times per week significantly reduced the $\mathrm{HbA1c}$ levels and insulin requirements. In another study, which was even more convincing, is a large cross-sectional study of over 19,000 children with type $1 \mathrm{DM}$, finding that the amount of physical activity was one of the strongest factors predicting lower HbAlc values [8]. However, little is known about the mechanism of action to explain the lowered the levels of blood glucose with exercise. The impact of exercise on blood glucose can be explained by the following:

There are two general sites where exercise could directly affect blood glucose (BG) regulation:

1- Insulin secretion of the islets.

2- Insulin-stimulated glucose uptake in the skeletal muscle [911]. There are couple of papers that have directly examined the first possibility: changes in insulin levels with exercise in type $1 \mathrm{DM}$. Unfortunately, the only assay used was an immunohistochemical measurement of the number of hormone-positive cells in the islets of exercised diabetic rats $[12,13]$. Clearly, more must be done to begin to unravel the cellular changes occurring in islets with exercise training.

Joslin, in the 1950s first suggested that exercise should be an essential component to regulate blood glucose levels of people with type $1 \mathrm{DM}$, along with a restricted diet and insulin therapy [14]. Yet, today the mechanisms by which exercise regulates blood glucose in conditions of

*Corresponding author: Louay Labban, FADA, CCN, CNC, RD, A'Sharqyiah University, Ibra, Oman, Tel: 011963992553309; E-mail: drlouay@gmail.com

Received December 15, 2014; Accepted March 04, 2015; Published March 10 2015

Citation: Labban L (2015) Can Physical Activity Reduce the Need of Medications for Diabetes Mellitus Management? J Diabetes Metab S13: 015. doi:10.4172/2155 6156.S13-015

Copyright: (c) 2015 Labban L. This is an open-access article distributed under the terms of the Creative Commons Attribution License, which permits unrestricted use, distribution, and reproduction in any medium, provided the original author and source are credited. 
type 1 DM are not explained. In the 1980s, classic work by Reaven and Chang showed that exercised rats with T1D had lower plasma glucose and triglyceride levels than their sedentary counterparts [15].

They hypothesized that the results were due to improved peripheral insulin sensitivity; however, no direct measure of islet mass or insulin content was reported is the first to measure exercise-induced increases in insulin content and secretion in isolated islets from diabetic animals.

That exercise could act by protecting islets during the onset of the disease, because in animal models of type $2 \mathrm{DM}$, long-term aerobic exercise resulted in increased islet $\beta$-cell proliferation, increased $\beta$-cell mass, and a partial sparing of the abnormal islet morphology noted in the sedentary diabetic rats [16]. Exercise blocked the age-associated morphological changes in the pancreas, including multi lobulated, fibrotic islets [17]. In addition, aerobic exercise decreased the presence of proinflammatory cytokines in islet cells [18], but did not change the islet gene expression pattern in type 2 Zucker diabetic fatty rats [19].

Morphological examination of the islets from our exercised-trained mice failed to demonstrate differences compared to the sedentary diabetic group. Our findings are similar to a previous report investigating the effect ofthe exercise on the distribution of $\alpha$-, $\beta$-, and $\delta$-cells and pancreatic polypeptide cells in the islets of streptozotocininduced diabetic rats [12]. Conversely, another study focused on $\beta$-cell health and exercise in type $1 \mathrm{DM}$ concluded that exercise partially spared the $\beta$-cells from diabetes [13]. A difference between the exercise protocols may explain the discordant results. In our protocol and the previous paper by Howarth et al., which showed no change in $\beta$-cell numbers, the exercise protocol was initiated after the induction of diabetes [12]. In the Coskun et al. study, the aerobic exercise protocol was initiated four weeks prior to the induction of diabetes and the exercise continued for another eight weeks to the termination of the experiment [13]. Thus, exercise may beable to protect $\beta$-cells if initiated prior to the onset of the disease but has limited or no ability to rescue the $\beta$-cells once lost. In conclusion, this is the first time that insulin content and secretion has been directly measured in type $1 \mathrm{DM}$ animals following exercise training. In fact, only two other publications have focused on the direct effects of exercise on islets under diabetic conditions $[12,13]$.

During moderate-intensity exercise in nondiabetic persons, the rise in peripheral glucose uptake is matched by an equal rise in hepatic glucose production, the result being that BG does not change except during prolonged, glycogen-depleting exercise. In individuals with type 2 diabetes performing moderate exercise, BG utilization by muscles usually raises more than hepatic glucose production, and BG levels tend to decline [20]. Plasma insulin levels normally fall, however, making the risk of exercise-induced hypoglycemia in anyone not taking insulin or insulin secretagogues minimal, even with prolonged PA. Most benefits of PA on type 2 diabetes management and prevention are realized through acute and chronic improvements in insulin action [21-25]. The acute effects of a recent bout of exercise account for most of the improvements in insulin action, with most individuals experiencing a decrease in their BG levels during mild- and moderateintensity exercise and for 2-72 $\mathrm{h}$ afterward $[8,26,27]$.

BG reductions are related to the duration and intensity of the exercise, preexercise control, and state of physical training $[8,11,20,21,28]$. Although previous PA of any intensity generally exerts its effects by enhancing uptake of BG for glycogen synthesis $[16,26,29]$ and by stimulating fat oxidation and storage in muscle [4,30,31], more prolonged or intense PA acutely enhances insulin action for longer periods [30,32-36].
During exercise, AMP is produced which stimulates AMPK enzyme. AMPK is an evolutionary conserved sensor of cellular energy status that is activated during exercise [37]. Pharmacological activation of AMPK promotes glucose uptake, fatty acid oxidation, mitochondrial biogenesis, and insulin sensitivity resulting in decrease in BG levels [32]. Exercise promotes glucose uptake by an insulin dependent mechanism involving AMPK. Exercise is important for improving insulin sensitivity; however, it is not known if AMPK is required for these improvements.

Participation in regular PA improves BG control and can prevent or delay onset of type 2 diabetes [31,38-42]. Prospective cohort and crosssectional observational studies that assessed PA with questionnaires showed that higher PA levels are associated with reduced risk for type 2 diabetes, regardless of method of activity assessment, ranges of activity categories, and statistical methods [43-45]. Both moderate walking and vigorous activity have been associated with a decreased risk, and greater volumes of PA may provide the most prevention [46]. Observational studies have reported that greater fitness is associated with a reduced risk of developing type 2 diabetes $[47,48]$, even if only moderate-intensity exercise is undertaken.

Women diagnosed with GDM are at substantially increased risk of developing type 2 diabetes; therefore, PA may be considered a tool to prevent both GDM and possibly type 2 diabetes at a later date [49]. Prepregnancy PA has been consistently associated with a reduced risk of GDM [50-54]. Studies during pregnancy are sparse, with only one case-control study [55], one retrospective study [56], and one study of a cohort of Hispanic women [57] observing significant protective effects of PA, while others have not [51-53,58].

Engaging in 30 min of moderate-intensity PA (e.g., brisk walking) during most days of the week (e.g., $2.5 \mathrm{~h} /$ week) has been adopted as a recommendation for pregnant women without medical or obstetrical complications. However, few primary prevention studies have examined whether making a change in PA reduces risk of developing GDM [59]. Only moderate intensity and duration of activity are needed to be effective in preventing diabetes. Three to five times/week, spaced at no more than 48-hour intervals, 15-60 minutes per session, with warm up and cool down period of approximately 5 minutes. Exercises can be like brisk walking, jogging or running, swimming, bicycling, tennis, badminton, skiing, or dancing. A period of proper warm up and cool down at low intensity level for 5-10 minutes is advised [60].

\section{Conclusion}

Exercise plays a major role in the prevention and control of insulin resistance, prediabetes, GDM, type 2 diabetes, and diabetes-related health complications. Physical activity affords significant acute and chronic benefits for those with type 2 diabetes. Both aerobic and resistance training improve insulin action, at least acutely, and can assist with the management of BG levels, lipids, BP, CV risk, mortality, and QOL, but exercise must be undertaken regularly to have continued benefits and likely include regular training of varying types. Most persons with type 2 diabetes can perform exercise safely as long as certain precautions are taken. The inclusion of an exercise program or other means of increasing overall PA is critical for optimal health in individuals with type 2 diabetes. Unfortunately, physical activity is underutilized in the management of type 2 diabetes. This may be due to lack of understanding and/or motivation on the part of the person with diabetes and lack of clear recommendations, encouragement, and follow-up by health care professionals. Health care professionals must address physical activity more seriously in this patient population 
Citation: Labban L (2015) Can Physical Activity Reduce the Need of Medications for Diabetes Mellitus Management? J Diabetes Metab S13: 015. doi:10.4172/2155-6156.S13-015

because most people with type 2 diabetes have the potential to derive benefits from regular, moderate levels of physical activity.

\section{References}

1. Aljasem LI, Peyrot M, Wissow L, Rubin RR (2001) The impact of barriers and self-efficacy on self-care behaviors in type 2 diabetes. Diabetes Educ 27: 393 404

2. American Diabetes Association (2010) Standards of medical care in diabetes 2010. Diabetes Care 33: S11-S61

3. U.S. Department of Health and Human Services Centers for Disease Control and Prevention National Diabetes Fact Sheet: General Information and National Estimates on Diabetes in the United States, 2007. Atlanta (GA): U.S Department of Health and Human Services Centers for Disease Control and Prevention; 2008

4. R D'hooge, T Hellinckx, C Van Laethem (2011) Influence of combined aerobic and resistance training on metabolic control, cardiovascular fitness and quality of life in adolescents with type 1 diabetes: a randomized controlled trial. Clinical Rehabilitation 25: 349-359.

5. Zeqiri A, Ylli, N Zeqiri (2007) The effect of physical activity in glycemia in patients with diabetes mellitus, Medicinski Arhiv 61: 146-149.

6. Faulkner MS (2010) Cardiovascular fitness and quality of life in adolescents with type 1 or type 2 diabetes. J Spec Pediatr Nurs 15: 307-316.

7. Michaliszyn SF, Faulkner MS (2010) Physical activity and sedentary behavior in adolescents with type 1 diabetes. Res Nurs Health 33: 441-449.

8. JPH Seeger, DHJ Thijssen, K Noordam, MEC Cranen, MTE Hopman, et al (2011) Exercise training improves physical fitness and vascular function in children with type 1 diabetes. Diabetes, Obesity and Metabolism, 13: 382-384.

9. Mayhan WG, Arrick DM, Patel KP, Sun H (2011) Exercise training normalizes impaired NOS-dependent responses of cerebral arterioles in type 1 diabetic rats. Am J Physiol Heart Circ Physiol 300: H1013-1020.

10. Nadeau KJ, Regensteiner JG, Bauer TA, Brown MS, Dorosz JL, et al. (2010) Insulin resistance in adolescents with type 1 diabetes and its relationship to cardiovascular function. J Clin Endocrinol Metab 95: 513-521.

11. Mann CJ, Ayuso E, Anguela XM, Bosch F (2010) Skeletal muscle metabolism in the pathology and treatment of type 1 diabetes. Curr Pharm Des 16: 1002 1020.

12. Howarth FC, Marzouqi FM, AI Saeedi AM, Hameed RS, Adeghate E (2009) The effect of a heavy exercise program on the distribution of pancreatic hormones in the streptozotocin-induced diabetic rat. JOP 10: 485-491.

13. Coskun O, Ocakci A, Bayraktaroglu T, Kanter M (2004) Exercise training prevents and protects streptozotocin-induced oxidative stress and beta-cell damage in rat pancreas. Tohoku J Exp Med 203: 145-154.

14. Robertson K, Adolfsson P, Scheiner G, Hanas R, Riddell MC (2009) Exercise in children and adolescents with diabetes. Pediatr Diabetes 10 Suppl 12: 154 168

15. Reaven GM, Chang F (1981) Effect of exercise-training on the metabolic manifestations of streptozotocin-induced diabetes in the rat. Diabetologia 21 $415-417$

16. Király MA, Bates HE, Yue JT, Goche-Montes D, Fediuc S, et al. (2007) Attenuation of type 2 diabetes mellitus in the male Zucker diabetic fatty rat: the effects of stress and non-volitional exercise. Metabolism 56: 732-744.

17. Reaven EP, Reaven GM (1981) Structure and function changes in the endocrine pancreas of aging rats with reference to the modulating effects of exercise and caloric restriction. J Clin Invest 68: 75-84.

18. Teixeira de Lemos E1, Reis F, Baptista S, Pinto R, Sepodes B, et al. (2009) Exercise training decreases proinflammatory profile in Zucker diabetic (type 2) fatty rats. Nutrition $25: 330-339$

19. M Colombo, S Gregersen, M Kruhoeffer (2005) Prevention of hyperglycemia in Zucker diabetic fatty rats by exercise training: effects on gene expression in insulin-sensitive tissues determined by high-density oligonucleotide microarray analysis. Metabolism 54: 1571-1581.

20. Minuk HL, Vranic M, Marliss EB, Hanna AK, Albisser AM, et al. (1981) Glucoregulatory and metabolic response to exercise in obese noninsulindependent diabetes. Am J Physiol 240: E458-464.
21. Huang HH, Novikova L, Williams SJ, Smirnova IV, Stehno-Bittel L (2011) Low insulin content of large islet population is present in situ and in isolated islets. Islets 3: 6-13.

22. Cohen ND, Dunstan DW, Robinson C, Vulikh E, Zimmet PZ, et al. (2008) Improved endothelial function following a 14-month resistance exercise training program in adults with type 2 diabetes. Diabetes Res Clin Pract 79: 405-411.

23. Ibañez J, Izquierdo M, Argüelles I, Forga L, Larrión JL, et al. (2005) Twiceweekly progressive resistance training decreases abdominal fat and improves insulin sensitivity in older men with type 2 diabetes. Diabetes Care 28: 662-667.

24. Ishii T, Yamakita T, Sato T, Tanaka S, Fujii S (1998) Resistance training improves insulin sensitivity in NIDDM subjects without altering maximal oxygen uptake. Diabetes Care 21: 1353-1355.

25. Winnick JJ, Sherman WM, Habash DL (2008) Short-term aerobic exercise training in obese humans with type 2 diabetes mellitus improves whole-body insulin sensitivity through gains in peripheral, not hepatic insulin sensitivity. $J$ Clin Endocrinol Metab 93: 771-8.

26. Galbo H, Tobin L, van Loon LJ (2007) Responses to acute exercise in type 2 diabetes, with an emphasis on metabolism and interaction with oral hypoglycemic agents and food intake. Appl Physiol Nutr Metab 32: 567-575.

27. O'Gorman DJ, Karlsson HK, McQuaid S (2006) Exercise training increases insulin-stimulated glucose disposal and GLUT4 (SLC2A4) protein content in patients with type 2 diabetes. Diabetologia 49: 2983-92.

28. Cohen ND, Dunstan DW, Robinson C, Vulikh E, Zimmet PZ, et al. (2008) Improved endothelial function following a 14-month resistance exercise training program in adults with type 2 diabetes. Diabetes Res Clin Pract 79: 405-411.

29. Sigal RJ, Kenny GP, Boulé NG, Wells GA, Prud'homme D, et al. (2007) Effects of aerobic training, resistance training, or both on glycemic control in type 2 diabetes: a randomized trial. Ann Intern Med 147: 357-369.

30. Duncan GE, Perri MG, Theriaque DW, Hutson AD, Eckel RH, et al. (2003) Exercise training, without weight loss, increases insulin sensitivity and postheparin plasma lipase activity in previously sedentary adults. Diabetes Care 26: 557-562.

31. Goodpaster BH, Katsiaras A, Kelley DE (2003) Enhanced fat oxidation through physical activity is associated with improvements in insulin sensitivity in obesity. Diabetes 52: 2191-2197.

32. O'Neill HM (2013) AMPK and Exercise: Glucose Uptake and Insulin Sensitivity. Diabetes Metab J 37: 1-21.

33. Williams SJ, Wang Q, Macgregor RR, Siahaan TJ, Stehno-Bittel L, et al. (2009) Adhesion of pancreatic beta cells to biopolymer films. Biopolymers 91: 676 685.

34. M Srinivasan, CS Choi, P Ghoshal (2010) B-cell specific pyruvate dehydrogenase deficiency impairs glucosestimulated insulin secretion. American Journal of Physiology 299: E910-E917.

35. Evans EM, Racette SB, Peterson LR, Villareal DT, Greiwe JS, et al. (2005) Aerobic power and insulin action improve in response to endurance exercise training in healthy 77-87 yr olds. J Appl Physiol (1985) 98: 40-45.

36. Houmard JA, Tanner CJ, Slentz CA, Duscha BD, McCartney JS, et al. (2004) Effect of the volume and intensity of exercise training on insulin sensitivity. $J$ Appl Physiol (1985) 96: 101-106.

37. Larsen JJ, Dela F, Madsbad S, Galbo H (1999) The effect of intense exercise on postprandial glucose homeostasis in type II diabetic patients. Diabetologia 42: $1282-1292$

38. Hamman RF, Wing RR, Edelstein SL, Lachin JM, Bray GA, et al. (2006) Effect of weight loss with lifestyle intervention on risk of diabetes. Diabetes Care 29 2102-2107.

39. Knowler WC, Barrett-Connor E, Fowler SE, Hamman RF, Lachin JM, et at. (2002) Reduction in the incidence of type 2 diabetes with lifestyle intervention or metformin. N Engl J Med 346: 393-403.

40. Laaksonen DE, Lindström J, Lakka TA, Eriksson JG, Niskanen L, et al. (2005) Physical activity in the prevention of type 2 diabetes: the Finnish diabetes prevention study. Diabetes 54: 158-165.

41. Li G, Zhang P, Wang J, Gregg EW, Yang W, et al. (2008) The long-term effect of lifestyle interventions to prevent diabetes in the China Da Qing Diabetes Prevention Study: a 20-year follow-up study. Lancet 371: 1783-1789. 
Citation: Labban L (2015) Can Physical Activity Reduce the Need of Medications for Diabetes Mellitus Management? J Diabetes Metab S13: 015. doi:10.4172/2155-6156.S13-015

42. Tuomilehto J, Lindström J, Eriksson JG, Valle TT, Hämäläinen $\mathrm{H}$, et al. (2001) Prevention of type 2 diabetes mellitus by changes in lifestyle among subjects with impaired glucose tolerance. N Engl J Med 344: 1343-1350.

43. Helmrich SP, Ragland DR, Leung RW, Paffenbarger RS Jr (1991) Physical activity and reduced occurrence of non-insulin-dependent diabetes mellitus. $\mathrm{N}$ Engl J Med 325: 147-152.

44. Hu FB, Sigal RJ, Rich-Edwards JW, Colditz GA, Solomon CG, et al. (1999) Walking compared with vigorous physical activity and risk of type 2 diabetes in women: a prospective study. JAMA 282: 1433-1439.

45. Manson JE, Rimm EB, Stampfer MJ, Colditz GA, Willett WC, et al. (1991) Physical activity and incidence of non-insulin-dependent diabetes mellitus in women. Lancet 338: 774-778.

46. Hu FB, Sigal RJ, Rich-Edwards JW, Colditz GA, Solomon CG, et al. (1999) Walking compared with vigorous physical activity and risk of type 2 diabetes in women: a prospective study. JAMA 282: 1433-1439.

47. Sui X, Hooker SP, Lee IM, Church TS, Colabianchi N, et al. (2008) A prospective study of cardiorespiratory fitness and risk of type 2 diabetes in women. Diabetes Care 31: 550-555.

48. Wei M, Gibbons LW, Mitchell TL, Kampert JB, Lee CD, et al. (1999) The association between cardiorespiratory fitness and impaired fasting glucose and type 2 diabetes mellitus in men. Ann Intern Med 130: 89-96.

49. Dyck RF, Sheppard MS, Cassidy H, Chad K, Tan L, et al. (1998) Preventing NIDDM among aboriginal people: is exercise the answer? Description of a pilot project using exercise to prevent gestational diabetes. Int J Circumpolar Health 57: $375-8$.

50. Dempsey JC, Butler CL, Sorensen TK, Lee IM, Thompson ML, et al. (2004) A case-control study of maternal recreational physical activity and risk of gestational diabetes mellitus. Diabetes Res Clin Pract 66: 203-215.

51. Dempsey JC, Sorensen TK, Williams MA, Lee IM, Miller RS, et al. (2004) Prospective study of gestational diabetes mellitus risk in relation to maternal recreational physical activity before and during pregnancy. Am J Epidemiol 159: 663-670.

52. Dyck R, Klomp H, Tan LK, Turnell RW, Boctor MA (2002) A comparison of rates, risk factors, and outcomes of gestational diabetes between aboriginal and non-aboriginal women in the Saskatoon health district. Diabetes Care 25: 487-93.

53. Oken E, Ning Y, Rifas-Shiman SL, Radesky JS, Rich-Edwards JW, et al. (2006) Associations of physical activity and inactivity before and during pregnancy with glucose tolerance. Obstet Gynecol 108: 1200-1207.

54. Zhang C, Solomon CG, Manson JE, Hu FB (2006) A prospective study of pregravid physical activity and sedentary behaviors in relation to the risk for gestational diabetes mellitus. Arch Intern Med 166: 543-548.

55. Liu J, Laditka JN, Mayer-Davis EJ, Pate RR (2008) Does physical activity during pregnancy reduce the risk of gestational diabetes among previously inactive women? Birth 35: 188-195

56. Perkins B, Riddell M (2006) Type 1 diabetes and exercise: using the insulin pump to maximum advantage. Can J Diabetes 30: 72-79.

57. Bweir S, Al-Jarrah M, Almalty AM, Maayah M, Smirnova IV, et al. (2009) Resistance exercise training lowers $\mathrm{HbA} 1 \mathrm{c}$ more than aerobic training in adults with type 2 diabetes. Diabetol Metab Syndr 1: 27.

58. Colberg SR, Sigal RJ, Fernhall B, Regensteiner JG, Blissmer BJ, et al. (2010) Exercise and type 2 diabetes: the American College of Sports Medicine and the American Diabetes Association: joint position statement. Diabetes Care 33: e147-167.

59. ACOG Committee Obstetric Practice (2002) ACOG Committee opinion Number 267, January 2002: exercise during pregnancy and the postpartum period. Obstet Gynecol 99: 171-173.

60. Nagi D, Gallen I (2010) ABCD position statement on physical activity and exercise in diabetes on behalf of the Association of British Clinical Diabetologists Committee. Pract Diab Int 27.
This article was originally published in a special issue, Type 2 Diabetes Mellitus- Disease, Diagnosis \& Treatment handled by Editors. Dr. Judit Bene, University of Pécs, Hungary; Eun Seok Kang, Yonse University College of Medicine, Korea 